\title{
The philosophy of expertise: the case of Vatican astronomers
}

\author{
Louis Caruana S.J.
}

The philosophy of expertise represents an interesting new research program in the area of science and religion. It is particularly significant because it refers not to particular scientific discoveries, considered individually, but to the general dynamics of the practical side of science. The crucial concept, expertise, involves the appeal to authority for the justification of arguments. Many people like to think that scientific knowledge is far from all appeal to authority. Those who are directly involved in scientific practice however know that science is not so clean. Appeal to authority remains very much part of the natural sciences, whether we like it or not. Some philosophers have recently ventured into these somewhat dark caverns of scientific thought and practice, and the result of their work has become very significant. In this paper, I will first offer a brief overview of this philosophical work, and then explore how the new insights regarding scientific expertise and scientific appeal to authority can throw light not only on how science works but also on the issue of authoritative knowhow within the Church. To avoid getting lost within the world of abstract principles, I will focus on one concrete case, the case of Vatican astronomers. This is a particularly interesting case because this group's complex role lies precisely at the intersection between theological and scientific expertise. We can focus on one concrete question that allows us to see how such abstract principles work. Our target question is "For policies involving scientific issues, can ecclesiastical decision makers like Bishops in Rome ever be genuine experts and genuinely authoritative when they are not scientists?" It should be evident that I intend this question to represent difficult episodes such as the 1968 encyclical Humane Vitae in which Paul VI rejected most forms of birth control, the 1983 US Catholic Bishops' Pastoral Letter on War, Peace and Nuclear deterrence, and some of the current mounting criticism against Pope Francis's Laudato Si. 
In these and similar cases, people criticize the Church for allegedly sticking its nose into scientific issues where it has no competence.

\section{Expertise in scientific practice}

Current work on the nature of expertise within science is the fruit of a long philosophical project that emerged from the work of Ludwig Wittgenstein, especially his insights about the importance of what people do for determining what they mean. Practice is the bedrock of semantics. Meaning is use. Such inspiring ideas were applied to various philosophical areas of inquiry by Wittgenstein's successors, one of whom, Gilbert Ryle in his 1949 book The concept of mind, derived the important epistemological distinction between knowing-that and knowing-how. The former kind of knowledge is propositional. We can factor out knowledge-that piecemeal into bits of information, with various kinds of inferential links between them. This is our normal view of knowledge. The other kind of knowledge, knowledge-how, is involved in the acquisition of practical skills: knowing how to the sail a boat, knowing how to ride a bike. Ryle's bold affirmation, one that we now recognize as a breakthrough, was that knowledge-how cannot be reduced to knowledgethat, in spite of our impression that it can. If you know how to ride a bike, it is not because you have learnt a long set of propositions or rules to guide you in all foreseeable situations. We say you acquire a skill precisely because what you acquire lies at a different level. If you try to think through your cycling, chances are that the propositions would confuse you and you would topple over. From here, we can see the possibility of having some individuals becoming very good in a skill, and thereby becoming a model for others. We call them experts. The last phase in this very quick historical sketch I am offering came with the pioneering work of Michael Polanyi whose books Personal Knowledge (1958) and The Tacit Dimension (1966) brought Ryle's discussion to the heart of scientific practice. These works remain very relevant today, especially because of their defence of the idea that scientific work, even though guided by rules, relies on personal judgements. 
Science is not an engine that churns out truths blindly. Even its most formalized areas depend on prior personal commitments. We believe more than what we can prove, and we know more than what we can describe in propositional form. The role of practice therefore becomes central, and with it that of the expert. ${ }^{1}$

Let me now bring the discussion to the frontline of current research and innovation. My focus will be an important recent study on scientific expertise by Harry Collins and Robert Evans, entitled Rethinking Expertise. ${ }^{2}$ We can describe their overall approach as philosophical sociology because it involves a clarification of the basic conceptual tools needed for the understanding of expertise. In short, their book presents a careful taxonomy of different kinds of expertise, identifies the different questions that scholars need to address, makes a bold proposal about experts who are directly engaged and those who are less engaged, as I will describe shortly, and then offers various case studies of scientific practice as a support for their general thesis. Since this paper is not meant to describe all this in detail, I will move on directly to the main idea that I think can serve as a useful bridge between scientific and ecclesiastical practices.

This concerns one of the distinctions that Collins and Evans discover between what they call contributory expertise and interactional expertise. For them, we can understand expertise in a very broad sense. Every disposition that a person can acquire is in a way a proto-expertise, or a "ubiquitous expertise", even if this disposition is not spectacular in any way or is not limited to specific individuals. For instance, we can take all Chinese people as experts in speaking Chinese. I consider this very broad sense of expertise of little use, but Collins and Evans have a point in highlighting that, even in this very broad sense, expertise depends on tacit knowledge rather than on logical calculation. To acquire expertise, you cannot depend only on the learning of explicit rules. You need enculturation; you need to spend time to absorb the skill via direct physical interaction.

\footnotetext{
${ }^{1}$ In this paper, I focus on science. It may be interesting to recall that the question of expertise within ethics has a longer history. Some recent scholars have tried to discredit it within this realm of moral philosophy, but their case is very weak. For a short overview of this debate, see Peter Singer, "Moral experts", Analysis 32 (1972): 115-117.

${ }^{2}$ Harry Collins and Robert Evans, Rethinking Expertise (University of Chicago Press, 2007).
} 
Polanyi had famously discussed riding a bike as a case of tacit knowledge because the physics involved is too complex for those wanting to learn. Some recent critics have challenged this by saying that there is nothing in principle against the possibility of having a large-enough intelligence that can codify and manage all the strict laws of nature involved. Collins and Evans rightly block this objection because cases of tacit knowledge are not designated as such simply because of the personal difficulty they would imply had they been just a matter of applying explicit rules. They are designated as such because they involve an added dimension of social-group feedback mechanisms. Think of riding a bike just before the start of lectures in some busy university campus. The skill involves interpreting the intention of others. This additional dimension shows that only social beings like humans can master such skills. ${ }^{3}$

Contributory expertise corresponds to the idea of expertise that we have in our everyday life. Collins and Evans define it as the kind of expertise that "enables those who have acquired it to contribute to the domain to which the expertise pertains" (p. 24). It involves the internalization of physical skills through stages: the stage of the novice, the stage of the beginner, the stage of the competent, and the stage of the expert. The expert in this sense has the ability to do things within that domain, which could be riding a bike, doing original research in the physics of gravitational waves, conducting open-heart surgery, and so on. There is, however, another kind of expertise, a kind that often goes unnoticed. Collins and Evans call it interactional expertise, which corresponds to the kind of expertise that is acquired by those who, although not direct contributors themselves, are so familiar with the contributory experts and with their domain that they come to "know all about it". The basic idea is that you can interact so much and in such fine detail with open-heart surgeons that you will eventually become an expert, even though you never conduct open-heart surgery yourself. Collins and Evans explain: "The idea of interactional expertise implies that the

\footnotetext{
${ }^{3}$ The point the authors are making is not that only humans are good at interpreting the intention of others. Some nonhuman animals are, in a sense, perfectly capable of such interpretation and can thus acquire various skills that are comparable to those available to humans. The point is rather that some skills are only possible because humans are capable of interpreting what other humans want, desire or wish. The point here gains plausibility when we recall that human mental states can be highly masked and intricate.
} 
complete fluency in the language of a specialist domain can be obtained in the absence [italics in the original] of full-blown physical immersion in the form of life" (p. 30-31). This is the thesis proposed and defended by Collins and Evans that I think can throw light on authority and expertise within the Church. Put simply, the idea is that one acquires contributory expertise within a specific domain by doing things; one acquires interactional expertise by interacting verbally only. Moreover, Collins and Evans make the bold claim that, from the viewpoint of a third party who seeks advice, the two kinds of expertise are indistinguishable.

\section{Expertise within the Church}

We move on now to ecclesiastical practice. I need first to express some caution because the question regarding the nature of authority in the Church is obviously vast. There are many distinct kinds of authority we can consider (such as doctrinal, governmental, juridical, and so on), and the debate has a very long history, some of its fundamental ingredients having been part of the teaching of Jesus himself. One way of specifying my focus is to concentrate on the notion of expertise. In the ecclesiastical context, expertise refers to the way the community acknowledges some of its members as having a special kind of knowhow that is useful for the entire community in certain circumstances. The main questions that come to mind here are the following. Who are the experts in the Church? Is there a role for the non-experts in the determination of the correct answer to a particular question? As I mentioned at the beginning, our analysis would be sharper if we make such general and abstract questions more concrete. Hence, the focus question "For policies involving scientific issues, can ecclesiastical decision makers ever be genuine experts when they are not scientists?"

Various theological areas are relevant here. Let me mention briefly the three main ones. First, we have the area that deals with the very nature of authority. In general, authority is a requirement for effective united action within a group. Since humans are political animals, some 
forms of authority are inevitable even though every form of authority remains in tension with the notion of individual interiority. Ecclesiastical authority follows this general pattern but highlights the divine origin of authority. The church is a society with both a supernatural and a natural dimension. For unified action to be possible, both these dimensions require structures of authority. Institutional authority has characterized the Church since its origins but so have charismatic forms of authority. The debate on the nature of expertise can throw new light on these distinctions, especially as regards the way authoritative individuals acquire their status. A second theological area deals with the juridical sense of authority and expertise. As described concisely in Canon 228, "lay persons who excel in necessary knowledge, prudence, and integrity are qualified to assist the pastors of the Church as experts and advisors, even in councils according to the norm of law." ${ }^{4}$ The main point regarding authority and expertise here is significant for the analysis I am presenting in this paper. It highlights the interaction between pastors and experts. The distinction between contributory and interactional expertise is already evident. Before proceeding with this reflection, however, let me mention one last theological area that can be very relevant: the locus of the sensus fidelium. The basic idea here is that we should not consider decision-making in the Church an exclusively top-down affair. We should see it rather as a complex dialogical process that includes the hierarchy and also the expertise gained by the laity via their day-to-day direct engagement with the world. Some interpretations of the sensus fidelium bring out this dimension very clearly. For instance, Zoltan Alszeghy interprets the sensus fidelium as an underlying structured synthesis of lived reality understood in the light of the Gospel. For Karl Rahner, it is a precognitive and comprehensive grasp (Vorgriff) of reality. ${ }^{5}$ Such views highlight the hidden, implicit grasp of a way of life, which gives lay people a kind of fundamental knowhow, a kind of contributory expertise.

\footnotetext{
${ }^{4}$ Codex iuris canonici, Vatican City: Libreria Editrice Vaticana, 1983; the English version, Code of Canon Law, is available online: http://www.vatican.va/archive/ENG1104/_INDEX.HTM

${ }^{5}$ Z. Alszeghy, "The Sensus Fidei and the Development of Dogma," in: Vatican II: Assessment and Perspectives Twenty-Five Years after (1962-1987), 3 v., ed. R. Latourelle (New York 1988) 1:138-56. For Rahner, see "The Faith of the Christian and the Doctrine of the Church," Theological Investigations 14 (New York: Crossroad, 1976) 24-46; “A Hierarchy of Truths," Theological Investigations 21 (New York: Crossroad, 1988) 162-67; "The Act of Faith and the Content of Faith," ibid., 151-61; "What the Church officially teaches and what the people actually believe,"
} 
Given this background, let us now apply some of the insights we drew from the work of Collins and Evans to the situation of the Church. Practicing scientists are in fact contributory experts. Their day-to-day experience helps them acquire the most fundamental type of expertise that is relevant in this area. The non-scientist clergy who interact seriously and continuously, in a learning mode, with this group of contributory experts can acquire, as Collins and Evans explain, the corresponding interactional expertise. If we were to follow Collins and Evans all the way, we would even say that the clergy's interactional expertise can eventually extract so much of the essential features of the contributory expertise that the two kinds of expertise will be indistinguishable for a third party. So, regarding the role of expertise, church practice is not out of step with what we find acceptable in scientific practice and in mainstream social structures in general. Those who denigrate the role of experts within the Church are just expressing an unfounded prejudice. Of course, things can go wrong. To attain genuine interactional expertise, the bishops and other clergy concerned need to take interaction seriously. This condition however holds across the entire range of social practice, whether ecclesiastical, scientific, or other.

At this point in my argument, before I proceed further with the application of these insights to the case of Vatican Astronomers, I would like to express some reservations about the work of Collins and Evans especially about their bold claim that the two kinds of expertise eventually become indistinguishable. It seems that the justification for such indistinguishability between contributory and interactional expertise depends on a kind of Aristotelian view of practice, whereby a practice is conceivable as matter and from. The intellect of the one who interacts with the contributory expert can come to share, as it were, the formal aspect completely even if he or she does not engage practically. That "matter" of the practice, the practical concrete hands-on experience, can therefore be dispensed with. This is what Collins and Evans assume. In doing so,

Theological Investigations 22 (New York: Crossroad, 1991) 165-75; “The Relation between Theology and Popular Religion," ibid. 140-47. See also O. Rush, "Sensus Fidei: faith 'making sense' of revelation” Theological Studies 62 (2001): 231-61. 
they disagree with other protagonists in this debate, especially the brothers Hubert and Stuart Dreyfus, who defend the need of a body, a physical body, for the successful acquisition of skills. ${ }^{6}$ For the Dreyfus brothers, the direct engagement with the material aspect of the practice gives the upper hand to contributory expertise. Collins and Evans try to minimize this aspect, claiming that all we require is a "minimal body", just a brain to think, an ear to hear and a voice to express ourselves. On this crucial point, I tend to sympathize more with the Dreyfus brothers.

Dismemberment of humans into body and thought is too crude to be of any good. Moreover, communication is not just language, and social interaction is not just bodily interrelation. Language is continuous with physical behavior. Saying things is a kind of doing things. The idea of meaning is much broader than what we do with sounds.

Given this inevitable merging of matter and thought, of body and language, I am convinced that we cannot accept the equivalence between the two kinds of expertise. This does not mean that interactional expertise is useless or impossible. For instance, I would say that you do not need to be a neurosurgeon to understand the practice of neurosurgery. You do not need to be a full-time astronomer to understand the practice of astronomy. You can become an expert by speaking to many neurosurgeons and many astronomers. Your expertise however will never be the same as that of a neurosurgeon or of an astronomer. It would be an expertise from a different perspective. The best way forward in this debate, therefore, is to use the notion of perspectival appropriation of any given practice. Contributory experts appropriate the skill from one perspective (they are in the practice), while interactional experts appropriate it from another perspective (from outside the practice). Collins and Evans see the two kinds of expert as engaged in a competition of competence as regards a third party and they argue (referring to the Turing test for artificial intelligence) that the two kinds of expertise are indeed on the same level. It seems to me however that interactional experts are definitely detached from the material side, and this makes them truly deficient when

\footnotetext{
${ }^{6}$ Dreyfus, Stuart E.; Dreyfus, Hubert L., Mind over Machine: the power of human intuition and expertise in the era of the computer (New York: Free Press, 1986).
} 
compared to contributory experts. Nevertheless, being detached from the material side offers some benefits. It enables interactional experts to hover above, as it were, the various pockets of contributory experts. It allows them to make comparisons and relative evaluations that are inaccessible to the contributory experts. Interactional experts are freer to move around. Applied to the ecclesiastical situation, this means that although bishops and other clergy can never be experts as regards science in the same way as fulltime scientists, if they interact well enough with scientists, they can acquire genuine interactional expertise. They can acquire a kind of expertise that represents a valuable perspective on scientific practice, a perspective that, in a sense, is unavailable to fulltime scientists themselves.

\section{The case of Vatican astronomers}

If we now apply the foregoing insights to the case of Vatican Astronomers, we can highlight at least three important points. First, it should be obvious by now that Vatican Astronomers should be, and indeed are, contributory experts. They have the theoretical foundations, the knowhow, the skills, and the access to professional networks. The mission of the Vatican Observatory would be impossible otherwise. Secondly, the Vatican Observatory can continue to help the Universal Church by facilitating the acquisition of interactional expertise by ecclesiastical decision makers, at least some of them. If my analysis is correct so far, this means that the Vatican Observatory should allow and even encourage some ecclesiastical decision makers to interact with them regularly. We need to recall that ecclesiastical decision makers are often experts in non-scientific areas and that, for them, the Vatican Observatory would be the only possible contact with the world of fulltime scientists. My third and final point is a word of caution. The contributory expertise represented by the Vatican Observatory is obviously focused on astronomy only. This may not correspond exactly to the real needs of ecclesiastical decision makers who seek an interactional expertise on various fronts of the complex worldview associated with the various sciences. This is a genuine worry. Nevertheless, I 
am convinced that, although the Vatican Observatory does not have branches in biology, in nuclear physics, in human reproductive technology, and in other significant scientific frontiers, we should still consider it indispensable. Although it cannot offer everything, the amount it can offer is extremely valuable.

The various arguments presented in this paper are enough, I hope, to show that a study of expertise is indeed useful to explore the notion of authority in various social situations, including scientific and ecclesiastical ones. Of course, there is much more to say about every topic I mentioned. The little I said however seems enough to justify the following two main points, namely that, if we acknowledge the legitimate role of interactional expertise in science, we should also acknowledge it in church practice, and that the Vatican Observatory can be a good source of such interactional expertise to those who want it. ${ }^{7}$

\footnotetext{
${ }^{7}$ Other works consulted: M. J. Lacey and F. Oakley (eds.), The crisis of authority in Catholic modernity (Oxford University Press, 2011); Marie Ann Breitenbeck, The role of experts in ecclesial decision-making in the 1983 code of canon law (Ann Arbor MI: University Microfilms International, 1991); Steven Brint, In an age of experts: the changing role of professionals in politics and public life (Princeton University Press, 1994). I would like to thank my colleagues of the Vatican Observatory and Prof. Stjepan Marcelja of the Australian National University for their useful comments on a previous draft of this paper.
} 